\title{
La actualidad de la hermenéutica. Entrevista a Jean Grondin y Ramón Rodríguez
}

\section{The present of hermeneutics. An interview with Jean Grondin and Ramón Rodríguez}

\author{
Iñigo PÉrez Irigoyen, Antón SÁnchez Testas y María Jou García \\ (Universidad Complutense de Madrid)
}

Recibido: 05/02/2016

Aceptado: 05/04/2016

\section{Resumen}

De manera paradójica, la actualidad de la hermenéutica debe buscarse en su diálogo con la tradición filosófica. Diálogo que daría comienzo, en primer lugar, con su recepción de Husserl, la cual no se puede entender tanto como una traición al proyecto fenomenológico cuanto como un llevarlo hasta sus últimas consecuencias. En segundo lugar, la vuelta sobre el proyecto moderno (no concebida como destrucción sino como intento de comprensión) conduciría a un dialógo con Kant y a la discusión de la posición de un sujeto trascendental como condición de la objetividad. Es precisamente esta idea de diálogo la que define la hermenéutica como una apertura a lo otro en tanto que otro y no como un ejercicio de asimilación. Finalmente, si esta apertura al otro no cristaliza en un proyecto ético definido es, justamente, porque trata de pensar el fundamento de lo ético.

Palabras clave: hermenéutica, fenomenología, diálogo, tradición, historicidad, modernidad, objetividad.

\begin{abstract}
The present of hermeneutics resides in its dialogue with the philosophical tradition. First of all, this dialogue starts with its reception of Husserl, which cannot be understood as the betrayal of the phenomenological project but the attempt to take it to its logical conclusion. Secondly, the interest on the modern project (an interest that cannot be thought as a destruction but as an attempt to understand it) leads to a dialogue with Kant and to the debate about the position of the trascendental subject
\end{abstract}


as a condition of objectivity. It is precisely this idea of the dialogue which defines hermeneutics as an opening to the other and not as an exercise of assimilation. Finally, if this opening does not crystallize into a defined ethical project it is because it tries to think the foundation of ethics.

Keywords: hermeneutics, phenomenology, dialogue, tradition, historicity, modernity, objectivity.

P: ¿Cómo se relaciona la historicidad heideggeriana como condición trascendental de posibilidad con la noción de interpretación como estructura previa del comprender, que actúa también como condición de posibilidad? Teniendo en cuenta el proyecto fenomenológico de Husserl, ¿serían Heidegger y Gadamer "traidores" del proyecto de Husserl o se puede hablar de una continuidad?

Jean Grondin: Traición es una palabra fuerte. Sin duda hay continuidad en el afán de buscar las condiciones de posibilidad de la inteligibilidad, como decía el profesor Rodríguez ayer, pero esas condiciones de posibilidad del sentido y de la inteligibilidad resultan históricas, tienen que ver con la historia de alguien, con la cultura, con el idioma, la lengua y, naturalmente, también con las condiciones sociales; y, como decía José Manuel Romero, tienen que ver con las condiciones económicas, pero éstas son algunas de las condiciones, no son las únicas. Heidegger tiene un concepto concreto de historicidad y dice todo lo que hay que saber acerca de eso en el capítulo sobre la historicidad, en Ser y tiempo. Lo que propone Gadamer es que no hay que ver en la historicidad un límite del entender sino una condición de posibilidad que hace posible el entender. Esa ha sido la barrera para autores como Dilthey o Husserl: su pregunta era cómo superar la historicidad, veían en ella una amenaza, un peligro, y buscaron una forma de certidumbre y de seguridad en un tipo de saber metodológico. En el caso de Dilthey: cómo se puede asegurar la validez universal de los conocimientos en las ciencias humanas. Gadamer dice que eso es una recaída en las aporías del historicismo y un callejón sin salida. Valora estos intentos, pero afirma que hay que afrontar otros peligros que conlleva valorar la historicidad, que hay en la historicidad prejuicios negativos que hay que superar. Gadamer propone su propia respuesta. Para responder a vuestra pregunta, sin duda hay continuidad en la búsqueda de las condiciones de la inteligibilidad del sentido y de eso se trata con la "herencia" y el "cuidado" según las descripciones que encontramos en Heidegger y en Gadamer. Dejan atrás lo que les parece no fenomenológico en Husserl y, en cierta medida, en Dilthey. Esa es la crítica clara de Heidegger: que la fenomenología de Husserl no es lo suficientemente fenomenológica. 
P: Justo a modo de puntualización a lo que estaba diciendo, queríamos que se relacionara de alguna forma esa búsqueda de las condiciones de posibilidad con el modo en que tanto Heidegger como Husserl definen el estatuto de la objetividad del fenómeno, de su objeto de estudio, el modo en que definen el objeto. Si en Kant las condiciones de posibilidad entendidas desde el sujeto trascendental posibilitaban una objetividad, ¿qué sería en Heidegger o en Husserl eso que define el objeto de estudio?

J. Grondin: Para definir la objetividad no basta con destacar las condiciones de posibilidad en el sujeto o en el conocimiento; para mí, la condición de objetividad consiste en hacer justicia al objeto mismo, y las condiciones de objetividad son las condiciones que dicta el objeto. Eso es lo que dice Aristóteles: el tipo de certidumbre que se puede esperar de la matemática no es el mismo que el que se puede esperar en la ética. Esta es su crítica a Platón, y es una idea que retoma la hermenéutica. Para mí, entonces, las condiciones de objetividad consisten en el respeto al objeto, en hacer justicia al objeto. Por eso no me centro tanto en el término "condiciones de posibilidad", porque resulta muy kantiano, y el kantismo identifica estas condiciones solamente con las del sujeto. Sin embargo, si yo quiero hacer justicia al objeto, tengo que abrir mis ojos, mis oídos, y escuchar al objeto mismo: Die Sache selbst, a la cosa misma.

Ramón Rodríguez: Yo estoy completamente de acuerdo. El asunto esencial en la fenomenología es, a diferencia de los resultados del pensamiento de Kant -no de los inicios, sino de los resultados-, que se trata de dejar que las cosas mismas se muestren como son. Entonces hay que pensar más bien las condiciones de posibilidad como lo que permite que podamos estar cabe las cosas mismas. En ese sentido la fenomenología, cuando se pregunta por las condiciones de posibilidad del sentido, por lo que se está preguntando es por la posibilidad de que podamos tratar con las cosas mismas, no con representaciones de las cosas o con imágenes de las cosas; y toda la crítica de Husserl a la teoría de las imágenes, etc. parte de la idea de que hemos heredado una especie de "representacionismo" por el cual, en vez de tratar con la mesa, estamos tratando con una representación de la mesa, o con una imagen de la mesa, o con una imagen que está en mi cabeza de la mesa. Al revés, yo creo que son las cosas mismas aquello en lo que estamos metidos, y entonces la pregunta es cómo es posible eso. Para responder a esa pregunta hay que tener una teoría de la conciencia que haga posible ese hecho y no al revés. En ese sentido creo que Husserl, Gadamer y Heidegger están en la misma trayectoria.

P: No podía faltar una pregunta sobre modernidad y posmodernidad. Se reconocerá que Heidegger y la hermenéutica han sido pilares fundamentales en el debate en torno a la cuestión de la posmodernidad. Bien, la constante pregunta de Heidegger por el momento moderno, ¿debe entenderse como un intento de superación y, por lo tanto, como una pregunta desde fuera del marco moderno, o debemos 
entender, al contrario, el proyecto heideggeriano como una radicalización de la modernidad y, por tanto, dentro aún de los presupuestos de la modernidad?

R. Rodríguez: Yo creo que la pretensión básica de Heidegger, al menos después de Ser y tiempo, es una deconstrucción clara de la modernidad. Pretender otro comienzo que el comienzo moderno. Ir más atrás de la filosofía de la subjetividad. Heidegger ha radicalizado cada vez más la crítica de la subjetividad como una posición genuinamente moderna y, en ese sentido, se puede leer al segundo Heidegger como una especie de, no tanto anti-modernismo, cuanto un intento de ir a unas bases metafísicas anteriores a la constitución de la filosofía de la subjetividad. En Ser y tiempo el modo de pensar sigue siendo trascendental en buena medida. En cambio, el segundo Heidegger es un intento de no pensar de modo trascendental, y no sólo en lo que respecta al sujeto. El modo de pensamiento trascendental, el tipo de argumentación propia del pensamiento trascendental está indisolublemente unido a la filosofía de la subjetividad. Eso Heidegger lo ve muy claro después, pero no en la época de Ser y tiempo. Si se lee la conferencia de El final de la filosofia y la tarea del pensar, que es ya el final de Heidegger, es clarísimo: une todo eso a una especie de posición genuinamente moderna donde en el fondo no hay grandes diferencias entre Kant y la fenomenología.

J. Grondin: La pregunta es muy sutil. Sin duda existe ese afán de superar la modernidad, pero lo que hace Heidegger tiene raíces en el proyecto moderno. Por ejemplo, cuando habla de un nuevo inicio, es innegable que coincide con lo que la modernidad siempre quiso hacer. Pensando en Descartes y en Kant, sin ir más lejos: todo hasta mí ha sido un error que hay que destruir y que hay que poner en duda, dice Descartes; hay que poner a la luz las ilusiones de la metafísica, dice Kant, y sólo el camino crítico queda abierto. En esa medida hay algo de Descartes, algo de Kant en Heidegger, si bien con otro concepto de metafísica, con otra pregunta; y, en esta medida, hay algo de moderno en Heidegger. Y también hay esa otra dimensión en Heidegger: él no diría propiamente que quiere destruir la modernidad, sino que quiere entenderla. Lo mismo dice a propósito de la técnica. Heidegger afirma: "no tengo nada contra la técnica". Bueno... es muy osado decir esto. Pero es verdad que quiere entender su esencia, lo que es. Y con respecto a la modernidad ocurre lo mismo. Esto es algo que no se puede negar. No se puede negar la metafísica, no se puede hacer como si esa historia del ser no hubiera existido. Esto es Heidegger. Heidegger dice sólo que esa historia nos conduce a una inteligencia del ser como objeto, como Gegenstand, y conduce al Gestell, conduce a nuestra condición tal vez fatal, y pregunta si hay otro camino, otra posibilidad, otro inicio, otro entender posible del ser donde uno podría entender también, o donde otra apertura de la experiencia del Dios sería posible. Porque dice que, a partir del entendimiento del ser que tenemos, Dios no es nada más que un ídolo de la subjetividad, y eso no son para él los dioses que no responden a condiciones de posibilidad, que son verdaderamente 
dioses. Esto se nota en Heidegger, esta búsqueda de algo otro, utópico o no. Eso es otro afán. Quiere entender la modernidad. Pero posmodernidad no es una palabra que utilizara en ningún momento.

P: Ahora mismo, en el actual contexto politico, se ha vuelto a retomar el debate sobre la filosofía, sobre todo en España. La filosofia tiene que volver a defender su estatuto específico que le otorga un papel en el mundo académico. Entendemos que la hermenéutica en concreto ha definido la especificidad de la filosofía académica como una relectura constante de la historia de la filosofia. La pregunta es: ¿cuál es la actualidad de la hermenéutica como disciplina filosófica después de sus grandes debates en el siglo XX con la fenomenología, la teoría crítica y la deconstrucción, y cómo determina la hermenéutica la filosofía en la academia y qué puede aportar?

R. Rodríguez: La situación es que, con la última ley de educación, la filosofía casi desaparece del nivel pre-universitario, del nivel de la enseñanza secundaria. Eso no sólo supone un problema de tipo profesional para nuestros estudiantes, sino que digamos que tiene una determinada dirección, un cierto proyecto de lo que es la enseñanza en el cual la filosofía sobra, o parece estar de más. Esa es la situación. Yo creo que no tenemos que hacer una defensa gremial. Decimos mucho que la filosofía es el pensamiento crítico, y yo creo que lo fundamental es que la filosofía abre el ámbito de las posibilidades. Estudiar filosofía -como piensa la hermenéuticaimplica la inmersión en la tradición filosófica. Yo creo que lo que abre posibilidades de comprensión del mundo es, digamos -y esto tiene que ver con la historicidad-, paradójicamente la inmersión en la tradición, en nuestro caso, de la filosofía. Estudiar a Kant o a Hegel o a Aristóteles no sólo no cierra sino que abre el horizonte de lo comprensible y da posibilidades de entender lo que nos pasa mucho más que con la restricción puramente técnico-administrativa hacia la que quiere llevarse la enseñanza. No es que sea un pensamiento genuinamente crítico, también es crítica la ciencia, y otras formas de pensamiento. Se trata, sobre todo, de apertura de posibilidades de comprensión, abrir el horizonte de lo posible. Y eso se hace, paradójicamente, estudiando a Kant, por ejemplo. En ese sentido me parece fundamental señalar que buena parte de nuestras limitaciones para entender lo que nos pasa nos vienen de un encerrarse en el "presentismo" actualista. Sólo desde ahí se explica uno que haya que estudiar sobre todo masters en economía o en ciencias de la comunicación. La filosofía es, sin entrar en la cosa propiamente técnica, una posibilidad de entender el mundo que, si se desconoce, hace que quedemos muy encerrados, muy limitados a lo que fácticamente se da en cada caso. La hermenéutica tiene la enorme virtud de mostrar la importancia de la tradición precisamente porque retoma los grandes proyectos filosóficos. No es una crítica destructiva. Al revés, comparte las grandes pretensiones de los grandes filósofos. Entonces, instalados en ellos, se ven las posibilidades internas. No es un posmodernismo, en ese sentido. 
J. Grondin: No conozco la situación en España, pero los problemas son universales. Yo diría que la filosofía tiene un papel fundador en la universidad. No me imagino una universidad sin filosofía. Si no hay filosofía hay que cerrar la universidad. Es la filosofía la que plantea preguntas sobre la finalidad del saber, sobre la finalidad de la vida humana, sobre lo que buscamos en la ciencia, en la universidad... en la sabiduría, y la filosofía es el amor a la sabiduría, es la disciplina que se ocupa de esas preguntas básicas, fundamentales, de las cuales las otras disciplinas no tratan pero sí presuponen. La filosofía está ahí para brindar una orientación universal sobre las preguntas básicas del ser humano que se pueden formular de muchas maneras. Podríamos retomar las preguntas de Kant: qué puedo saber, qué debo hacer, qué me es permitido esperar. La filosofía es una disciplina básica y vivirá. Por lo que atañe a la hermenéutica, se trata de una manera de practicar la filosofía: una manera de practicar la filosofía en diálogo. El diálogo es el alma de la hermenéutica, el diálogo con los que no piensan como nosotros. Entonces, para mí, la hermenéutica es una actitud de apertura, de apertura a todo lo que tiene sentido, a todo lo que se puede defender. Es un afán de superar sus propias limitaciones. Como dice Gadamer, el alma de la hermenéutica es que el otro puede tener razón. Eso me parece muy esencial en nuestro tiempo, esa apertura a otros puntos de vista, y naturalmente apertura a su propia historia en la medida en que ya somos hijos e hijas de una historia que no podemos dejar atrás. La filosofía tiene una conciencia muy clara de eso, es una disciplina muy atada a su propia historia porque nuestra civilización, de la cual forma parte la universidad, tiene una historia constitutiva de lo que somos. Viene de los griegos, de los romanos, la Edad Media, la modernidad... Si uno quiere saber lo que se puede aprender de todas esas edades y otras culturas que también tienen algo que decir, hay que hacer hermenéutica, hay que abrirse a estas otras perspectivas. Para mí la hermenéutica es una sensibilidad, es una actitud, una manera de hacer filosofía que no es muy dogmática, que no parte de un a priori como otras formas de filosofía, como es el caso de la filosofía analítica que rechaza casi todo lo que haya sido hecho en el desarrollo de la filosofía, y que se ciñe a una concepción muy científica de lo que debe ser la argumentación filosófica. O la crítica de las ideologías, que pretende, ella misma, tener una certeza sobre el curso de las cosas humanas. Bueno, la hermenéutica no tiene esa certidumbre. Yo creo que se puede argumentar de muchas maneras y eso lo recuerda la hermenéutica. Empieza con el reconocimiento socrático de su propia ignorancia. Eso ha sido el inicio de la filosofía.

P: En relación con esto último que comentaba de la hermenéutica como un diálogo que está esencialmente abierto al otro, queríamos hacerle una pregunta retomando la noción de Vattimo, que presenta la hermenéutica como una nueva koiné o un nuevo espacio común para el diálogo, y el modo en que se relaciona precisamente esta noción de la universalidad de la hermenéutica que retoma tanto 
Gadamer como usted mismo en varias de sus obras, con unas criticas posibles que se le han hecho desde planteamientos alternativos, como es el caso de la teoría levinasiana de la alteridad radical, que presentan la hermenéutica como algo que no se hace cargo del otro sino que pretende neutralizarlo como otro.

J. Grondin: Como apertura, la hermenéutica está abierta a todas las críticas, y lo ha demostrado en sus representantes más fuertes, y aquí pienso sobre todo en Ricoeur o Gadamer. No conozco a filósofos que hayan discutido más con sus adversarios que esos dos pensadores. Gadamer ha discutido con mucho gusto con Habermas o con Derrida, por nombrar solo los más famosos. Pero Derrida no quería discutir, y Habermas era muy crítico con Gadamer, que era el más abierto en este debate. Habermas, como reconoció el propio Gadamer, mantiene posiciones relevantes. Ricoeur, por su parte, ha dialogado siempre con "enemigos" de la hermenéutica, como el estructuralismo o el psicoanálisis, en lo que pueden ya considerarse como sus debates épicos. No conozco una filosofía más abierta a sus críticos. Es decir, creo que la hermenéutica practica lo que enseña. Y por lo que atañe a Levinas: ¿cómo se puede decir que la hermenéutica no considera al otro cuando se considera, precisamente, la apertura al otro? No se ha entendido la hermenéutica si se considera que busca integrar o dominar al otro. El otro debe ser entendido como otro, ese es el desafío hermenéutico. Hay que estar abierto a cada alteridad, que a veces hay que combatir. Me refiero por ejemplo al Estado Islámico, que es la alteridad total. Yo puedo entender lo que es, pero ciertamente hay límites al entendimiento. La alteridad debe ser entendida. De hecho, cuando uno dice la palabra alteridad, uno está entendiendo algo. No veo, por lo tanto, cómo se puede superar aquí la exigencia hermenéutica del entender, que considero básica.

R. Rodríguez: Vosotros habláis de Levinas, al que yo no conozco lo suficiente como para dar una opinión taxativa sobre él, pero la impresión que siempre me producen este tipo de críticas es que parecen considerar que comprender al otro es ya en sí mismo, por el mero hecho de comprender, una especie de negación de su alteridad. Comprender sería, por lo tanto, asimilar, apropiarse, etcétera. Eso es una cuestión puramente teórica, cuando hablamos del otro hablamos de este o aquel otro. Cuando trato de dialogar con alguien se trata, como dice Gadamer, de dejar valer lo otro, al otro, la opinión del otro en sí misma, y tratar de entenderla. Y entendimiento no significa acuerdo o consenso. Entender no es lo mismo que aceptar o consensuar. Eso forma parte de la hermenéutica. Por lo que esa oposición entre comprensión y alteridad, honradamente, no la entiendo.

P: En una reciente conferencia el profesor Grondin ha demarcado la diferencia entre un primer proyecto de Heidegger en Ser y tiempo, con una pretensión trascendental, y un segundo proyecto, después de la kehre, en el que se esfuerza por pensar el ser en su acontecimiento, en su historicidad. Teniendo en cuenta la influencia de Kant en el proyecto de Ser y tiempo, ¿se podría entender el interés 
posterior por la cuestión de la historicidad como un alejamiento de Kant y un acercamiento a Hegel, considerando la referencia constante a este autor que hace Gadamer en Verdad y método?

J. Grondin: Aquí hay mucho que decir. Respecto a Kant: en una carta célebre de Heidegger a Jaspers, el primero le comenta: "comienzo a amar a Kant". Se enamoró de Kant, de un Kant muy particular. Hay que entender, sin embargo, por qué no sentía antes ese amor por Kant. El joven Heidegger, que procedía de una tradición aristotélico-tomista que veía en Kant el peor subjetivismo, albergaba un rechazo casi instintivo hacia Kant. Y sin embargo, ahí está la carta a Jaspers que refleja el cambio de posición, y eso se nota en muchos pasajes de Ser y tiempo. Para Heidegger, Kant había visto en algunos puntos de su obra el vínculo entre el ser y el tiempo, sobre todo en el esquematismo de los conceptos puros del entendimiento de la Crítica de la razón pura. Ahí Kant dice que los conceptos deben hablar, para ser aplicados, el idioma del tiempo. Kant sería la única excepción al olvido del vínculo entre ser y tiempo. Es el único, antes de Heidegger, en percibirlo, pero no pudo entender las razones del vínculo mismo. La falta de Kant es no haber leído Ser y tiempo [ríe], por eso Heidegger pretende ser más radical que Kant. En la lógica de Ser y tiempo se puede entender perfectamente lo que decía Heidegger. Por ello escribe un libro sobre Kant, imparte clases sobre Kant, inmediatamente después del 27 da un curso sobre Kant. Pero después llega el debate con Cassirer... y Heidegger se desenamora. Se desenamora, en primer lugar, de su propio proyecto, de la idea de desarrollar un esquematismo trascendental para entender el ser. Se pone a buscar otros autores, y encuentra a Hegel. Siempre había tenido cierta resistencia a Hegel, a pesar de haber impartido en el año 30 una conferencia titulada Hegel y el problema de la metafisica. Reconocía seguramente a Hegel en el ámbito histórico y filosófico, pero mantuvo que, en el fondo, lo que pretendía Hegel era suprimir el tiempo. Es lo que plantea Hegel al final de la Fenomenología del espíritu, en el saber absoluto. Es precisamente lo contrario de lo que pretende Heidegger, pensar la temporalidad del ser, pensar radicalmente la temporalidad. Esto tuvo unas consecuencias importantes. A partir de entonces Heidegger establece una continuidad entre el intento metafísico y el intento de superar el tiempo. Por eso durante esos años deja de hablar de metafísica. Después de Ser y tiempo, como François Jaran muestra muy bien, Heidegger, que buscaba desarrollar una metafísica del Dasein, rechaza la palabra metafísica tras su encuentro con Hegel y la convierte en su enemiga. Considera a la metafísica una enemiga para plantear la pregunta por el ser. ¡Y para mí esa es la ironía más fatal de la metafísica, que es la ciencia del ser y se caracteriza por su olvido! El evento más importante en la historia del ser es el olvido del ser. El acontecimiento de la metafísica es el olvido del ser. Habría aquí muchas más cosas que decir. A partir de entonces, es evidente que no habrá ninguna solidaridad entre Heidegger y Hegel o Kant. Los dos son para Heidegger representantes del pensa- 
miento metafísico. Reconoce que son importantes y difíciles de superar, pero ya no hay amor. Con todo, hay un nuevo amor: Hölderlin, y un poquito Nietzsche. Pero esta es una pregunta muy compleja. Ya hemos hablado un poco de ello: hay muchos amores importantes en el camino de Heidegger. ¿Y por qué se enamoró de Hölderlin, de Nietzsche? ¿Hay razones en el amor? Una pregunta difícil.

P: Para terminar, queríamos hacer una pregunta en torno a la relación que podría haber entre una fenomenología hermenéutica de corte heideggeriano y la pregunta por la ética. Volviendo a Kant, se sabe que el planteamiento que desarrolla en la Crítica de la razón pura es, precisamente, un intento por liberar el espacio para una futura Crítica de la razón práctica, una delimitación de la razón pura teórica para dejar paso a la razón pura práctica. ¿Se puede encontrar algo parecido en Heidegger o sencillamente es una pregunta que no puede plantearse?

R. Rodríguez: Creo que se ha entendido la fenomenología hermenéutica como el modo de tratar la pregunta por el ser, de llevar el ser a la comprensión, de forma que se ha entendido como un proyecto sólo muy secundariamente ético. De lo que se trataba era de ver el estar en el ahí del Dasein, con la idea fundamental de preparar la pregunta por el ser. Y eso es implícitamente ético en la medida en que los comportamientos ónticos que supone el estar en el mundo implican comportamientos éticos. Pero se trataba de ver el modo de ser, el tipo de ser que conlleva el Dasein. Es decir: ver cómo tiene que ser el Dasein para que pueda haber ética. Pero no entra en el terreno propio de la ética. Lo que pasa es que como el Dasein es un ser al que le va su propio ser, ese irle su propio ser implica una realización constante de sí mismo, y eso es, en un sentido amplio, práctica. La relación que tengo conmigo mismo no es una relación contemplativa sino práctica, de realización: eso es la matriz de la ética, si entendemos por ética qué tipo de comportamiento es bueno o malo. Heidegger diría que, bueno o malo, supone siempre realización de sí mismo. Son las bases de la ética, aunque sin tematizarla explícitamente. La misma idea de Ser y tiempo de apertura constante es una actitud, una actitud que es, digamos, el estar disponible a lo que puede abrir al otro. Y esa apertura es la condición básica para toda ética, de modo que hay una impronta ética sin que haya, sin embargo, un proyecto específico.

J. Grondin: Dice Heidegger en la Carta sobre el humanismo, que sería aquí la fuente más importante, que en la medida en que su analítica del Dasein quiere tematizar el ethos del ser humano, se puede ver como una ética originaria. Hay que pensar lo que somos. Ser y tiempo está lleno de consideraciones éticas que no se llaman a sí mismas éticas: cuando habla de conciencia, de solicitud, de cuidado, etc. Pero Heidegger no quiere pensar la ética en términos de medios de producción: tenemos una teoría y hay que aplicarla. Eso es demasiado fácil, es kantismo, en su manera de ver las cosas. La primera frase de Carta sobre el humanismo dice que no pensamos lo suficiente en las ideas antes de actuar. Eso es lo que Heidegger quiere hacer. 
Pretende liberar nuestra época de sus demonios tecnológicos, de su olvido del ser. Esa esperanza de Heidegger podría llamarse ética, aunque tampoco estoy muy seguro de ello: para Heidegger llamarlo ético sería demasiado poco. Él espera una salvación. Y su pensamiento está ahí para preparar un nuevo pensamiento. Está convencido de que las avenidas del pensamiento metafísico no brindan ninguna posibilidad más. Eso se puede criticar. Por eso yo digo que podría estar siendo ahí, quizás, un poco maniqueo. Gracias a Dios, nuestra tradición filosófica ofrece éticas muy interesantes, de Levinas hasta Aristóteles. Seguro que hay un intento ético, salvífico, en Heidegger, sin duda. Pero aquí no hay que quedarse, sin embargo, con Heidegger. Sí, es necesario tomar en serio lo que dice sobre las aporías de nuestro tiempo y criticar las soluciones fáciles. Un kantismo vulgar sería, para él, algo así como una broma vulgar.

Iñigo Pérez Irigoyen

Universidad Complutense de Madrid ipirigoyen@gmail.com

Antón Sánchez Testas

Universidad Complutense de Madrid antestas@gmail.com

María Jou García

Universidad Complutense de Madrid mariajou@estumail.ucm.es 